\title{
Development of a Novel Carbon-Fiber Mono-Lateral External Fixator
}

\author{
Desarrollo de un Fijador Eterno Mono-Lateral de Fibra de Carbono
}

\author{
W.A. Carabali-Satizabal ; J.J. García-Álvarez ;G. F. Casanova-García iD \\ DOI: https://doi.org/10.22517/23447214.23311 \\ Artículo de investigación científica y tecnológica
}

\begin{abstract}
This paper reports the design of an innovative monolateral external fixator made of carbon fiber composite materials. The designed system can be easily assembled in comparison with commercial fixators and follows orthopedic requirements with sufficient stability and stiffness. The change of operation mode between distraction and fixation is achieved with a wedge that blocks axial translation in one position, while allows sliding with a $90^{\circ}$ rotation. The prototypes were produced by the method of molding by compaction. A mold was developed for each part; the rail, the clamp and the cover. Each mold consisted of a cavity that gave form to the piece and a piston that exerted pressure on the composite. Mechanical tests were performed to determine the stiffness under axial compression, and anteroposterior and mediolateral bending. For comparison, tests were also performed on two Orthofix commercial systems, one with the rail made of carbon fiber and the other with an aluminum rail. The axial compression, anteroposterior and mediolateral bending stiffness of the developed system were $200.7,13.4$ and $87.0 \mathrm{~N} / \mathrm{mm}$, respectively, which were $38 \%, 35 \%$ and $27 \%$ lower than those obtained for the Orthofix system. However, these values were in the range of other similar systems reported in the literature. Therefore, the developed system presented promising results and may be clinically evaluated.
\end{abstract}

Index Terms - Bone transport, carbon fiber, distraction, external fixation, stiffness.

Resumen- Este artículo reporta el diseño de un novedoso fijador externo hecho material compuesto de fibra de carbono. El sistema diseñado es fácil de ensamblar en comparación con sistemas de fijación comerciales y cumple con requerimientos ortopédicos con suficiente estabilidad y rigidez. El cambio de modo de operación entre distracción y fijación se logra con una cuña que bloquea la traslación axial en una posición, mientras permite deslizamiento si se rota $90^{\circ}$. Los prototipos se construyeron con el método de moldeo por compactación. Se desarrolló un molde para cada parte: el riel, la prensa y la tapa. Cada molde consistió de una cavidad que da la forma a la pieza y un pistón que ejerce presión sobre el compuesto. Se realizaron ensayos mecánicos para determinar la rigidez a compresión axial

This manuscript was sent on January 10, 2020 and accepted on November 26, 2020. This work was supported by Universidad del Valle (Grant number CI 2923), Cali, Colombia and by COLCIENCIAS: programa nacional de ciencia tecnología e innovación en ingeniería, convocatoria 715-2015, contrato 2652016, código 110671551517.

W.A. Carabali-Satizabal is a Mechanical Engineer graduated from Universidad del Valle, Cali, Colombia.

(william.carabali@correounivalle.edu.co) y flexión anteroposterior y mediolateral. Para comparación, las pruebas se realizaron también sobre en dos sistemas comerciales Orthofix, uno con el riel hecho de fibra de carbono y otro con un riel de aluminio. Las rigideces a compresión axial, flexión anteroposterior y flexión mediolateral del sistema desarrollado fueron 200.7, 13.4, y 87.0 N/mm, respectivamente, las cuales fueron $38 \%, 35 \%$ y $27 \%$ menores que las obtenidas en el sistema Orthofix. Sin embargo, esos valores están en el rango de otros sistemas similares reportados en la literatura. Por lo tanto, el sistema desarrollado presentó resultados prometedores y puede pasar a una etapa de ensayos clínicos.

Palabras claves - Distracción, fibra de carbono, fijación externa, transporte óseo, rigidez.

\section{INTRODUCTION}

$\mathrm{M}$ ono-lateral external fixation systems are mechanical devices used to stabilizing bone fractures during the healing process or for bone transport through the principle of distraction osteogenesis or callotasis that was first discovered by Illizarov [1]. Bone transport is used to correct bone deformities or to fill gaps produced by comminuted fractures or tumors [2]. Basically, those systems are formed by screws, clamps, a rail, and a distractor. The screws are embedded into the bone segments at the threaded end and fixed to the rail with the clamps at the other end. There are three stages during the treatment, initial fixation followed by distraction and final fixation. In the initial stage, all the clamps are fixed to the rail to provide stability to the fracture site, which allows the formation of bone callus. During distraction, some clamps are loosened to allow axial displacement along the rail to separate one bone segment with respect to the other and create new tissue. Once the bone segment has reached the desired length, the mobile clamp is fixed to the rail and the system works as a common external fixator used to treat bone fractures. Fig. 1

J.J. García-Álvarez is a professor of School of Civil and Geomatics Engineering of the Universidad del Valle, Cali, Colombia.

(jose.garcia@correounivalle.edu.co)

F. Casanova is a professor of School of Mechanical Engineering of the Universidad del Valle, Cali, Colombia. (correspondence author)

(gonzalo.casanova@correounivalle.edu.co) 
shows a schematic representation of the distraction process.

It has been reported that controlled axial relative movement between bone fragments or Inter-fragmentary Displacement (IFD) is useful for callus formation [3]. Some studies even reported that increasing the axial stiffness of the fixation system reduces the healing rate $[4,5]$, which may due to reduced axial IFD because a high axial stiffness. On the other hand, transverse IFD, i.e. perpendicular to the bone axial direction, has been reported to negatively affect the healing process [6, 7]. Therefore, a fixation system has to provide appropriate stiffness to guarantee a good outcome during all stages of the healing process.

Among the mono-lateral systems more extensively used are the LRS Advanced-Orthofix (Orthofix SRL, Verona, Italy). In those systems the clamps can only be introduced into the rail from the ends and are fixed to the rail through a bolt located at the bottom of the clamp. For distraction, the bolt is loosened or removed to allow axial displacement of the clamp with respect to the rail. In this paper we report the development of a monolateral fixation system for bone transport, in which the clamps can be inserted laterally all along the rail and not only from the ends. The permutation from fixation to distraction is performed with a wedge that fixes the clamp to the rail in one position and allows axial displacement by a $90^{\circ}$ rotation. The entire system was designed and manufactured with a composite material of epoxy resin matrix reinforced with carbon fiber fabric. This provided translucency, thus allowing to evaluate the progress of the healing process using $\mathrm{X}$-rays without dismantling the system [8], as has to be done with traditional fixators made of metallic parts.

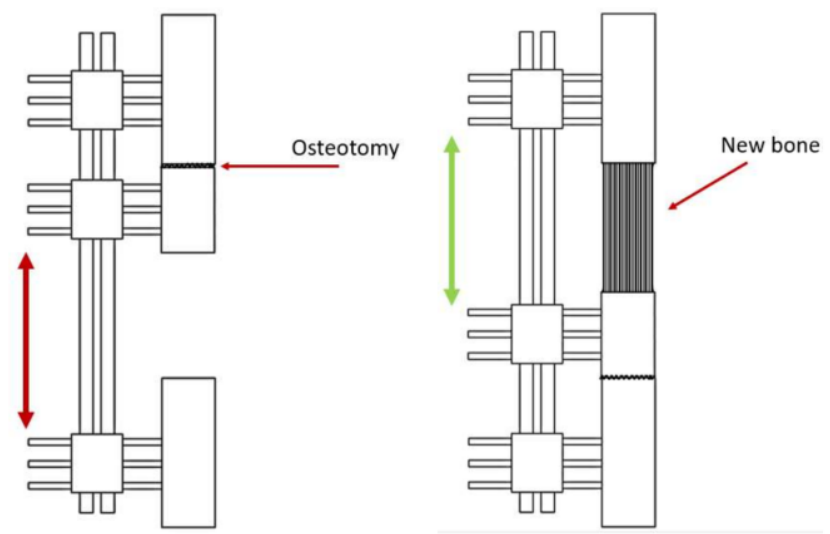

Fig. 1. Distraction process. Left: a osteotomy is performed in the upper bone segment. Right: the middle clamp is moved down and new bone is generated.

\section{Design Of The SYSTEM}

The first step in the design was the definition of the geometry of the rail. Initially, a rail of an approximately rectangular cross section with one beveled corner and one rounded corner was considered (Fig. 2). The inclined plane of the beveled corner was coupled with one face of the wedge while the rounded corner allowed having contact on the faces of the clamp. The system was formed by four main parts: the rail, the C-shaped clamps, the cover, and the wedge.
The function of the cover is to fix the screws to the clamp by two bolts. The clamp is attached to the rail by the wedge. The wedge is locked with a bolt that threads in the wedge and it is tight from the upper part of the cover, similar to the bolts that fix the cover to the clamp. This is an important feature of this system, which allows to tight all bolts from the upper face. This option facilitates the installation by the Orthopaedic Surgeon, different to the LRS Advanced-Orthofix models, where the bolt that fixes the clamp to the rail has to be tighten from the bottom.

The wedge operates in two positions to either fix the clamp to the rail or allow distraction. In one position (Fig.2b) the wedge is tight against the bevel plane of the rail and leaves a gap between the lower face of the clamp and the upper face of the wedge. Hence, when the bolt is tight, the axial movement of the clamp with respect to the rail is fixed. In the other position, accomplished after a $90^{\circ}$ rotation, the upper face of the wedge is tight against the lower face of the clamp, leaving a gap along the beveled surfaces so that the clamp-cover-wedge assembly can move with respect to the rail in the axial direction during the distraction stage (Fig. 2c). A section showing the gap in the surfaces is shown in Fig. 2d. The permutation between the two positions is easily achieved by a rotation of $90^{\circ}$ of the wedge with respect to the bolt.
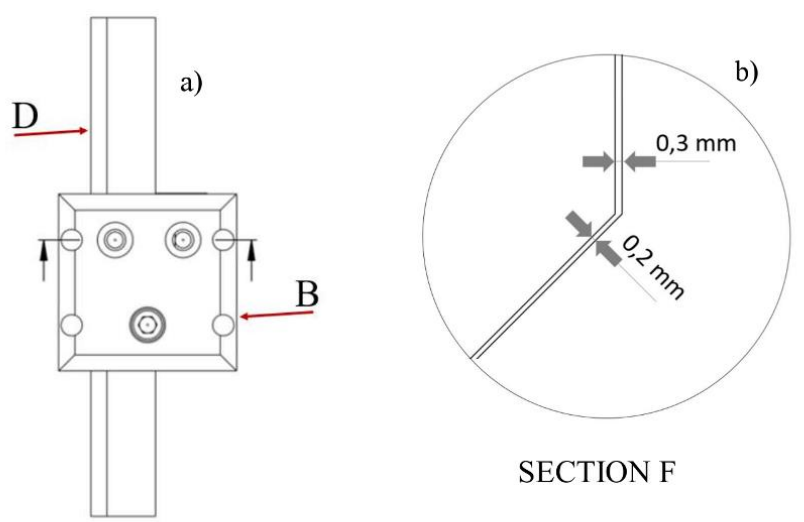

SECTION F
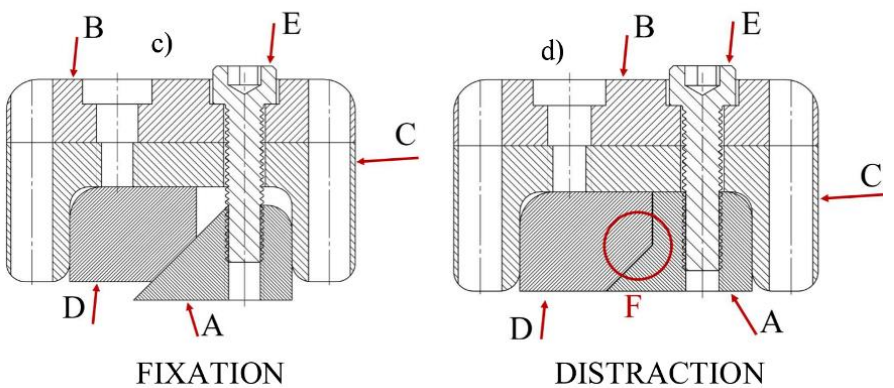

Fig. 2. Preliminary geometry of the system: a) top view of the system, b) section showing the gap between rail and wedge, c) cross section of the system assembled for fixation with the inclined plane of the wedge in contact with the rail, d) cross section of the system assembled for distraction with the upper face of the wedge in contact with the clamp. (A-wedge, B-cover, C-clamp, D-rail and E-Bolt).

To evaluate the functionality of the system, a first prototype was manufactured using 6061 aluminum. This prototype was assembled and manipulated many times, changing the wedge positions to achieve the two configurations (distraction and 
fixation). In general, a satisfactory operation was obtained. However, when the bolt was tight in the fixation mode, a notorious lateral deformation of the clamp was induced, due to the contact force on the inclined plane of the rail. This deformation also produced a rotation of the wedge, which in turn produced partial separation of the wedge with the rail as schematically shown Fig. 3.

To avoid the excessive deformation of the clamp, the geometry of the system was modified by changing the inclined plane in the rail and the wedge by a step, as shown Fig. 4. The final shape of the pieces is shown in Fig. 5.

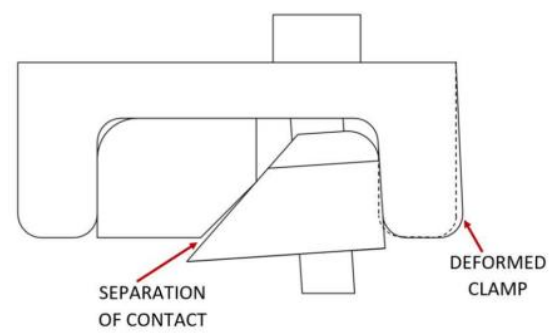

Fig. 3. Schematic representation of the deformed system with the wedge tight in fixation configuration.

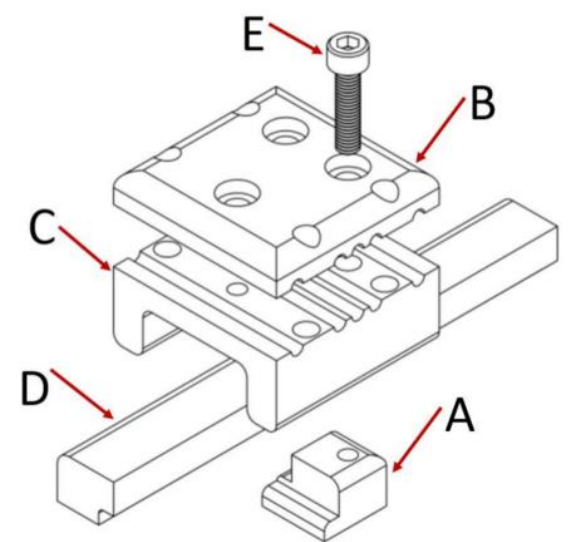

Fig. 4. Rail and wedge with stepped geometry (A-wedge, B-cover, C-clamp, Drail, and E-bolt).
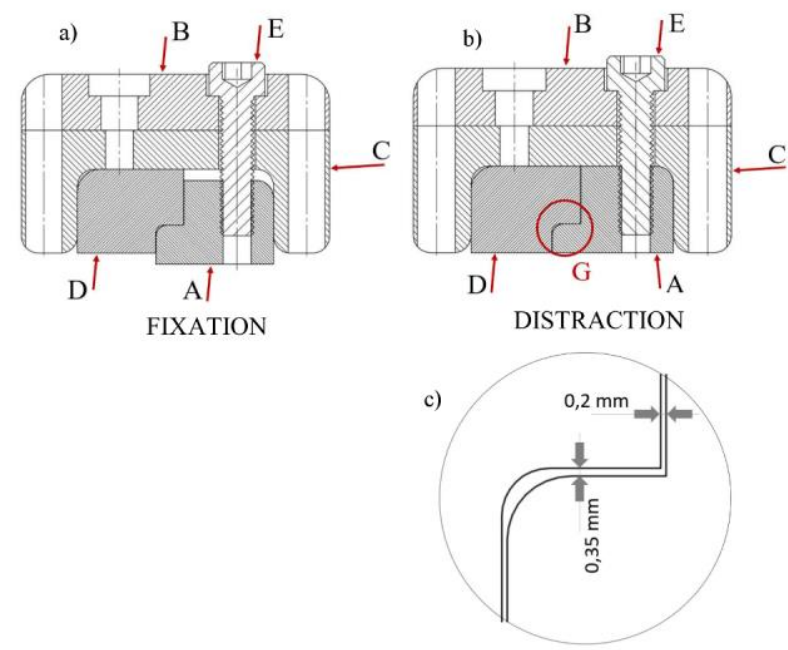

SECTION G

Fig. 5. Cross section of the fixation system with a rail of rectangular stepped geometry: a) wedge in fixation configuration producing contact with the rail, b) wedge tight against the clamp leaving a gap with the rail to allow axial displacement for distraction function, c) section showing the gap between rail and wedge (A-wedge, B-cover, C-clamp, D-rail and E-Bolt).

\section{MANUFACTURING}

In general, a fiber reinforced material is composed of a matrix of thermoset or thermoplastic polymers reinforced with fibers, which provide high strength and stiffness in fiber orientation. The function of the matrix is to transfer the loads between the fibers and give the shape to the composite. I our case, the parts were manufactured using plain wave $(1 \times 1)$ carbon fiber fabric with $200 \mathrm{~g} / \mathrm{m} 2,0.33 \mathrm{~mm}$, and $2538 \mathrm{~N} / \mathrm{m}$ of nominal density, thickness, and strength respectively. Epoxy resin was used as matrix.

Hand lay-up followed by compression inside a mold was the process used to build the pieces. A mold was designed for each part having a cavity with the shape of the component. Next, the fabric impregnated with resin was placed in the cavity and compressed with a piston. Fig. 6 through 8 shows the molds for the rail, clamps and covers. The molds for the clamps and covers were designed to produce three pieces per batch.
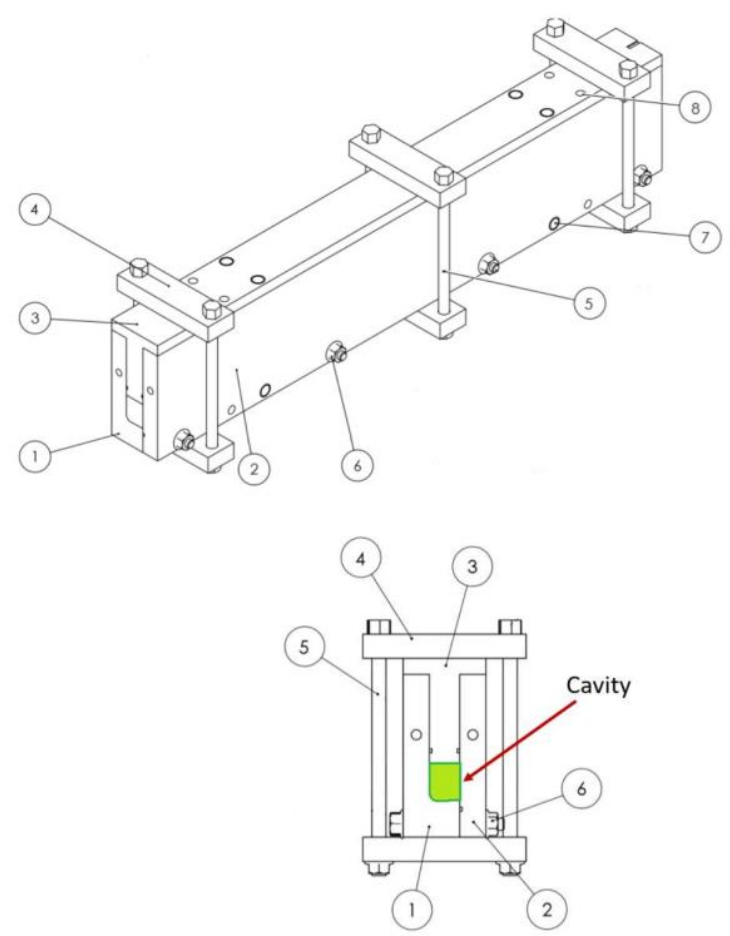

Fig. 6. Mold for the rail. Parts 1 and 2 form the cavity and part 3 is the piston. The bolts 5 are joined with the brace 4 , which was used to compress the piston against the fabric. Part 8 corresponds to guide pins. Bolts 6 join the parts 1 and 2. Number 7 shows the extractor holes of the mold. 


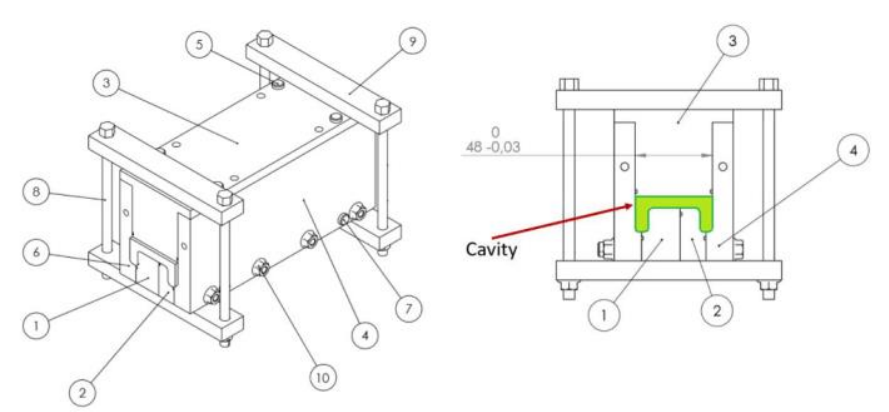

Fig. 7. Mold for the clamps. The cavity is formed by parts 1, 2, 4 and 6 joined by bolts 10 . The piston 3 is compressed by brace 9 against the fabric. Parts 5 and 7 are guide pins. The bolts 8 apply force on the brace to compress the mold.

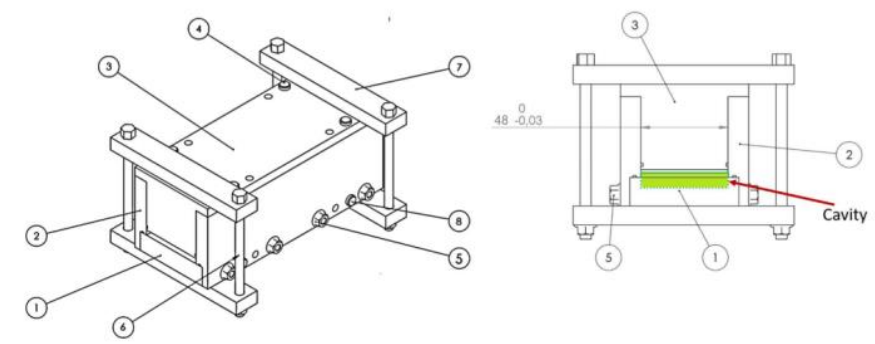

Fig. 8. Mold for the covers. The cavity formed by parts 1 and 2 are joined by bolts 5 . The fabric is compressed with the piston 3 using the braces 7 . Parts 4 and 8 work as guide pins. The bolts 6 apply force on the brace to compress mold.

To begin the manufacturing process, the resin was mixed with the catalyst in the proportion recommended by the provider. Then the resin was spread on the fabric using a spatula. The impregnated fabric was rolled around a thin metallic sheet or mandrel; the mandrel was immediately removed and the fabric was placed inside the mold and compressed with the piston during 24 hours at room temperature $\left(30^{\circ} \mathrm{C}\right.$ on average). Fig. 9 shows the stages of the molding process for the clamps. The amount of fabric was calculated to achieve a final proportion of $60 \%$ of fiber and $40 \%$ of resin in weight. During the pre-manufacturing process, the amount of fabric that was used to build the piece was weighed. Once the piece was built, it was weighed again. Then, the weight of the fabric over the weight of the piece yielded the fiber percentage. However, with this fiber ratio (60\%), several defects, such as lack of fiber around the grooves and internal voids were observed (Fig. 10). Therefore, the ratio fiber/resin ratio was increased to 70/30 obtaining defect-free pieces with a good surface appearance (Fig. 11). In a similar way, rails and covers of good quality were obtained with a fiber/resin ratio of $70 / 30$. The final ratio verified after the construction was 71.1/30.

After molding, machining was accomplished to make the holes for the bolts in the covers and the clamps and the step in the rails. Also, the wedges were manufactured from a bar. To avoid machining the composite, threads for the bolts were made in cylindrical Polyetheretherketone (PEEK) inserts. Next, those cylinder were bonded on the holes of the clamps and wedges. The outside diameter of the inserts was $10.2 \mathrm{~mm}$ and the thread was M6. The machined holes on the pieces were $11 \mathrm{~mm}$ of diameter. The PEEK cylinders were bonded by using an epoxybased product. Fig. 12 shows the machined pieces and Fig. 13 shows the pieces with the PEEK inserts. The assembled external fixation system is presented in Fig. 14.

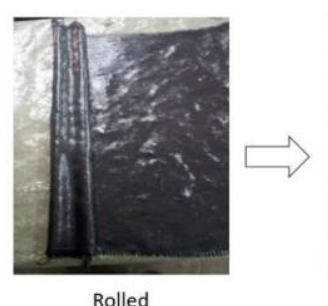

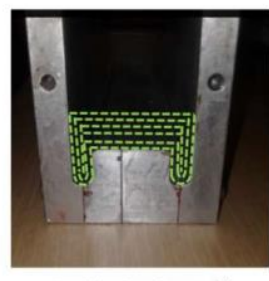

Positioning in mold

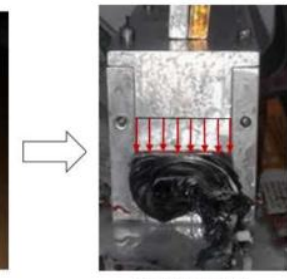

Compaction
Fig. 9. Technique to build the clamps. Green lines on the middle figure highlight the carbon fiber layers.

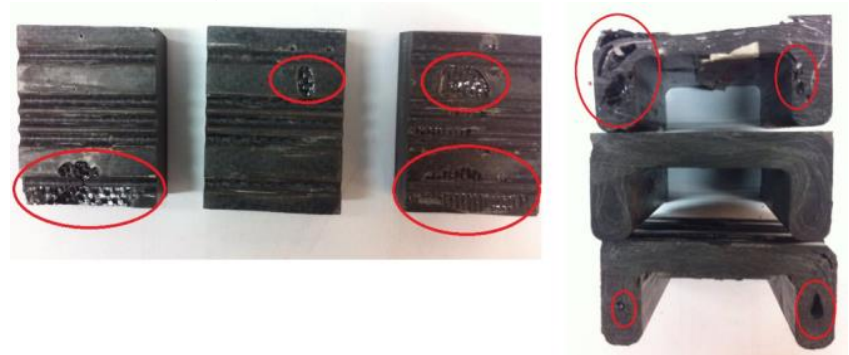

Fig. 10. Defects obtained in first prototypes of clamps with a fiber/matrix ratio of 60/40. Left: lack of fiber and resin around the grooves for the screws. Right: voids inside the clamps.

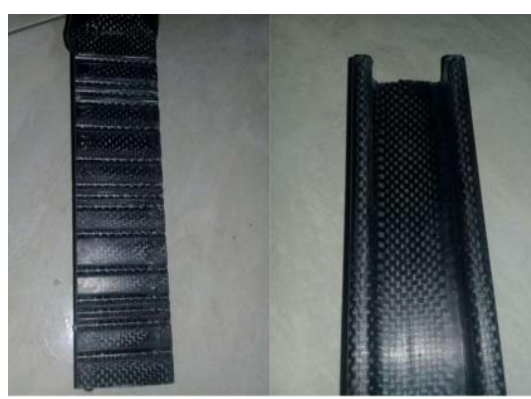

Fig. 11. Defect free clamps obtained by increasing the fiber-resin ratio to 70/30 in weight.
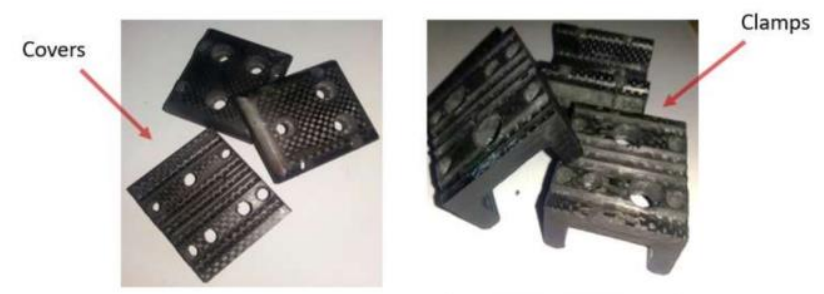

Rails
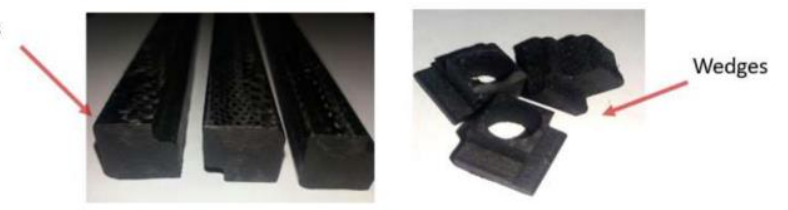

Fig. 12. Machined pieces 

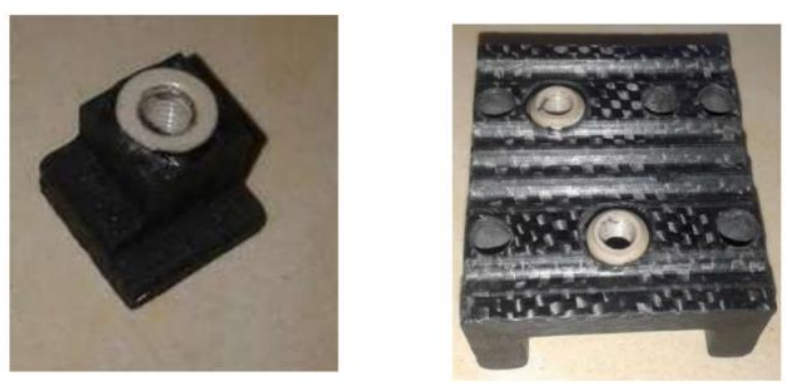

Fig. 13. Machined pieces with PEEK inserts. Left: wedge. Right: clamp.
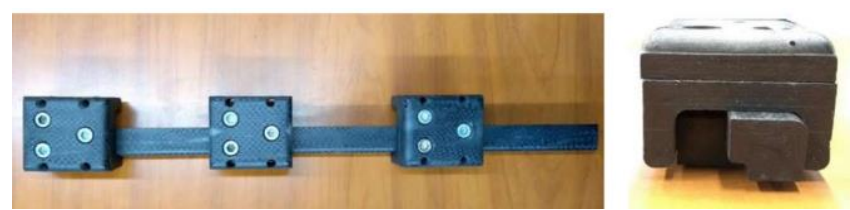

Fig. 14. External fixation system made of carbon fiber composite material.

\section{Mechanical Tests Methodology}

To evaluate the mechanical performance of the system, the stiffness under axial load, anteroposterior bending (AP), and mediolateral bending (ML) of three prototypes was measured according to the ASTM F1541 standard [9]. Figs. 15, 16, and 17 show the experimental set up for the axial, AP, and ML tests respectively. Mechanical tests were performed in a tension compression machine with capacity of $1800 \mathrm{~N}$. The force was measured with a LCM703 load cell (Omega Engineering, INC. Norwalk, CT) and the displacement was measured with a LD620 LVDT (Omega Engineering, INC. Norwalk, CT). Signals were registered with a NI USB-6221 data acquisition system (National Instruments. Austin, TX). The stiffness was determined as the slope of the load vs displacement curves.

For comparative purposes, the prototype made of aluminum presented in Section 2 and two LRS Advanced-Orthofix systems, one with a carbon fiber rail and the other with an aluminum rail were also evaluated. The clamps for both Orthofix systems were made of aluminum.

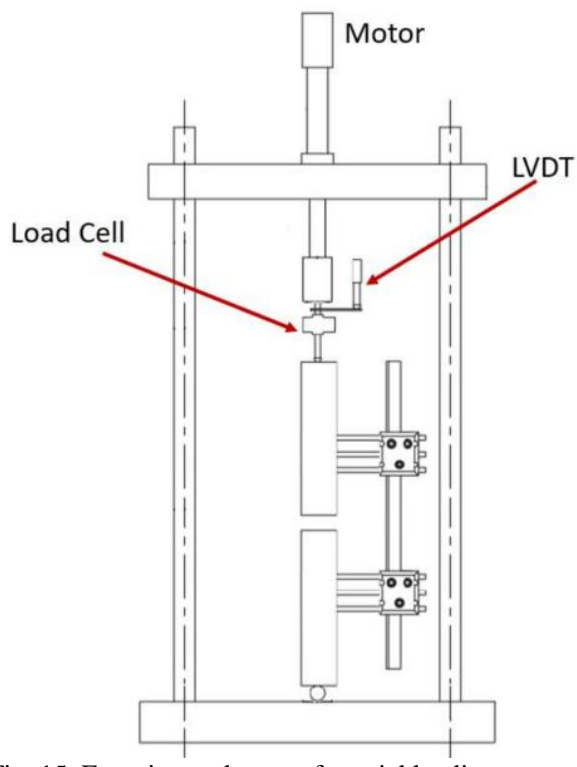

Fig. 15. Experimental set-up for axial loading.

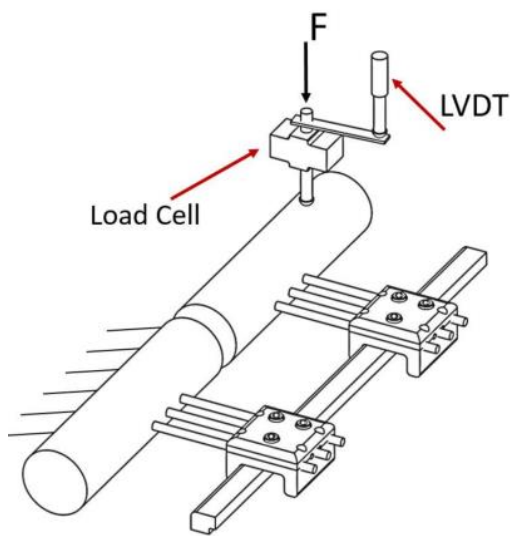

Fig. 16. Experimental set up to measure the anteroposterior (AP) stiffness.

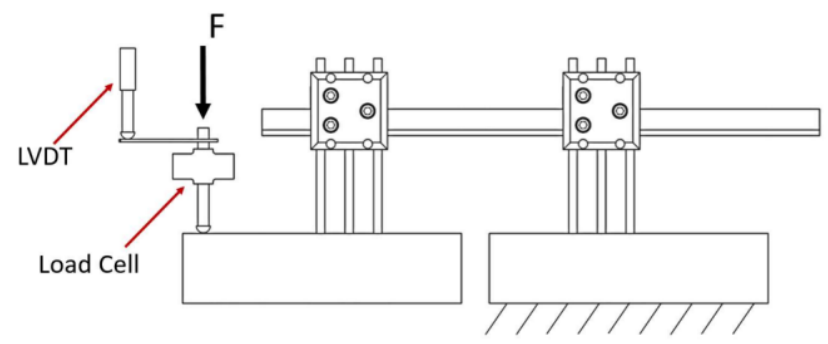

Fig. 17. Set-up to determine the mediolateral stiffness (ML).

\section{MECHANICAL TESTS RESUltS}

The stiffness of the carbon fiber prototypes was smaller than those of the aluminum models for each load case (Figs. 18-20). The ratio between the stiffness of the carbon fiber prototypes and the Orthofix carbon system was $0.62,0.65$, and 0.73 for the axial, AP, and ML load modes, respectively. 


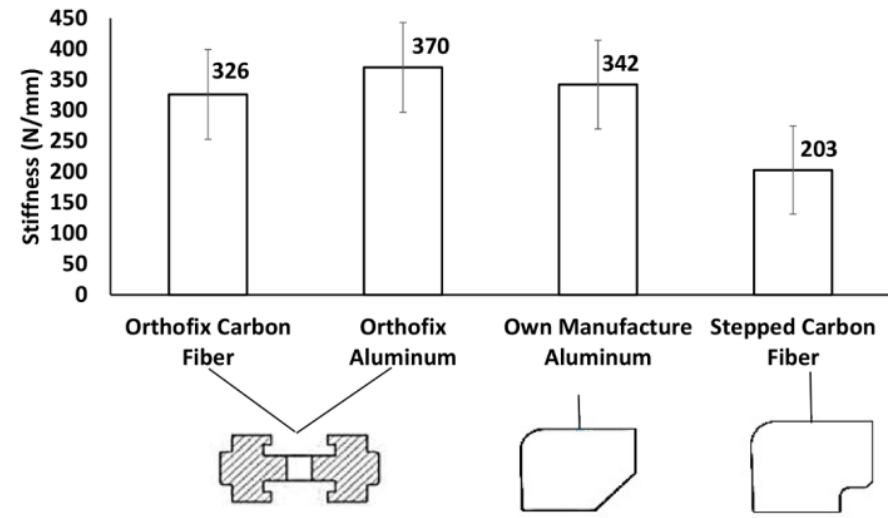

Fig. 18. Comparative analysis of experimental Axial Compression stiffness.

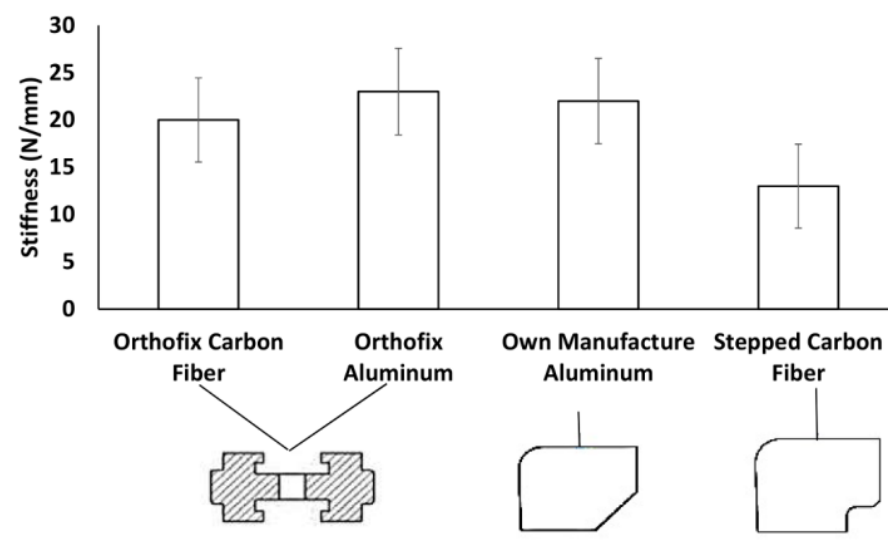

Fig. 19. Anteroposterior (AP) bending stiffness.

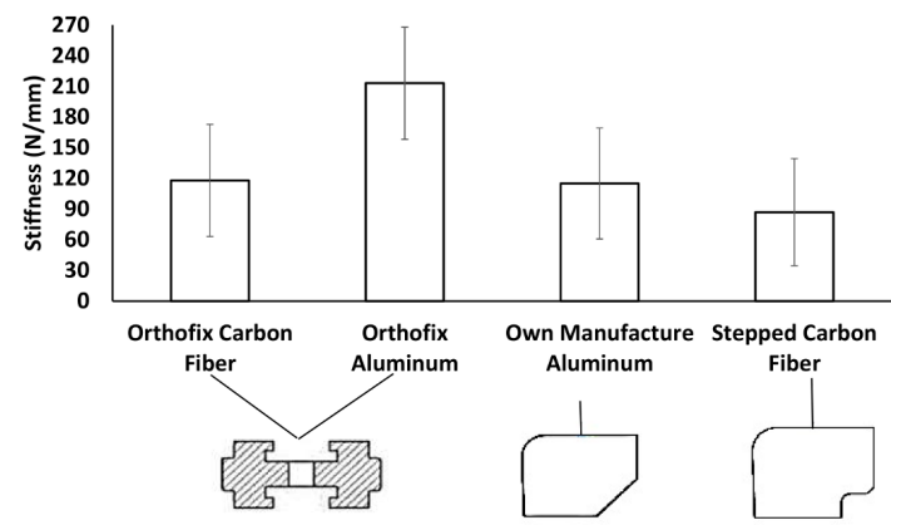

Fig. 20. Experimental Mediolateral (ML) bending stiffness.

\section{DISCUSSION}

A novel prototype of external fixation system for bone transport was built and evaluated by mechanical tests. The prototype has several improvements with respect to commercial systems: 1) the clamp can be laterally assembled all along the rail instead of only by the ends of the rail, 2) the permutation between fixation and distraction can be easily done by the rotation of $90^{\circ}$ of the wedge, 3 ) the bolt of the wedge has to be completely tight in both positions which avoids unclear condition of tightening or removal, 4) all the bolts are tighten from the upper face and not from the bottom, which facilitates installation, 5) the majority of the pieces are made of carbon fiber reinforced material or PEEK which are materials translucent to X-rays. The characteristics 1 to 4 make the system easy to assemble during surgery.

Mechanical tests showed that aluminum provides higher stiffness compared to carbon fiber systems. From all evaluated models, the developed carbon fiber prototypes presented the smallest stiffness, which can be explained by the lower moment of inertia of the rectangular rail cross section compared with the I-shaped rail of the Orthofix system.

Even though the carbon fiber prototype had smaller stiffness than the Orthofix, it is still higher than the stiffness of other systems reported in literature. For example, Gardner and Evans [10] evaluated the stiffness of six external fixation systems under different load modes and reported an axial stiffness ranging between 25 and $80 \mathrm{~N} / \mathrm{mm}$. Aro and Chao [11] found an axial stiffness as low as $50 \mathrm{~N} / \mathrm{mm}$ for the Ilizarov system, which has been successfully used in clinical applications for bone transport. In other load modes as AP bending, they also reported systems with stiffness smaller than those obtained in this study for the carbon fiber prototype.

In spite of the promising results obtained with the developed system, there are still some drawbacks that have to be overcome. An evaluation by an orthopedic surgeon indicated that the clamp-cover assembly is too big. Then, efforts have to be made in future studies to optimize the material for a reduction of the size without compromising strength. In addition, some inserts came off during the tests or even during tightening and had to be bonded again. This problem can be solved by making the hole and the insert with a tapered geometry.

\section{CONCLUSION}

A mono-lateral carbon fiber external fixator was designed, constructed and biomechanically evaluated to treat open fractures and to perform bone elongation.

A design with a wedge was proposed that facilitates switching from fixation to distraction.

The techniques and manufacturing parameters were established to build relatively complex pieces of carbon fiber reinforced material. Molds were manufactured that allows the simultaneous construction of three clamps.

The fixator showed stiffness values equal to $0.62,0.68$ and 0.73 times the stiffness of the Orthofix carbon fiber model, under conditions of axial compression, anteroposterior and mediolateral bending, respectively. However, the stiffness of the developed system are similar to other systems reported in the literature and used for bone transport. Therefore, the developed system may be evaluated by clinical trials.

\section{ACKNOWLEDGMENT}

The authors thanks to the Universidad del Valle (Grant number CI 2923), Cali Colombia, and to COLCIENCIAS: programa nacional de ciencia tecnología e Innovación en Ingeniería, convocatoria 715-2015, contrato 265-2016, código 110671551517 , for financial support. 


\section{REFERENCES}

[1] G. O. Paul, "The history of external fixation," Clinics in Podiatric Medicine, vol. 20, pp. 1-8, 2003. DOI: https://doi.org/10.1016/S0891-8422(02)00050-2

[2] Z. Yang, L. Jin, H. Tao, D. Yang, "Reconstruction of large tibial bone defects following osteosarcoma resection using bone transport distraction: A report of two cases," Oncology Letters, vol. 12, pp. 1445-1447, 2016. DOI: https://doi.org/10.3892/ol.2016.4777

[3] L. E. Claes, H. J. Wilke, P. Augat, S. Rubenacker, K. J. Margevicius, "Effect of dynamization on gap healing of diaphyseal fractures under external fixation," Clinical Biomechanics, vol. 10, no. 5, pp. 227-234, 1995.

[4] E. Goodship, P. E. Watkins, H. S. Rigby, J. Kenwright, "The role of frame stiffness in the control of fracture healing. An experimental study," Journal of Biomechanics, vol. 26, no. 9, pp. 1027-1035, 1993.DOI: https://doi.org/10.1016/S0021-9290(05)80002-8

[5] G. D. Krischak, A. Janousek, S. Wolf, P. Augat, L. Kinzl, L. E. Claes, "Effects of one-plane and two plane external fixation on sheep osteotomy healing and complications," Clinical Biomechanics, vol. 17, pp. 470-476, 2002. DOI: https://doi.org/10.1016/S0268-0033(02)00039-6

[6] Salcedo-Cánovas, "Bone elongation using monolateral external fixation: a practical guide," Strategies Trauma Limb Reconstruction, vol. 10, pp.175-188, 2015. DOI: https://doi.org/10.1007/s11751-015-0236-0

[7] M. Yamagishi, Y. Yoshimura, "The biomechanics of fracture healing,” J. Bone Joint Surg. Am., vol. 37, pp.1035-1068, 1955.

[8] Migliaresi, F. Nicoli, S. Rossi, A. Pegoretti, "Novel uses of carbon composites for the fabrication of external fixators," Composites Science and Technology, vol. 64, no. 6, pp. 873-883, 2004. DOI: https://doi.org/10.1016/j.compscitech.2003.09.003

[9] ASTM Standard Specification and Test Methods for External Skeletal Fixation Devices, ASTM standard F1541, 2015

[10] T. N. Gardner, M. Evans, "Relative stiffness, transverse displacement and dynamization in comparable external fixators," Clinical Biomechanics, vol. 7, no. 4, pp.231-239, 1992. DOI: https://doi.org/10.1016/S0268-0033(92)90006-P

[11] H. T. Aro, E. Y.S. Chao, "Biomechanical performance of the standard Orthofix External Fixator and cortical screws,", in: G. De Bastiani, A.G. Apley, A.J. Golderg (Eds.), Orthofix External Fixation in trauma and Orthopaedics, Springer, pp.45-70, London (2000).
William Alberto Carabali Satizabaland was born in Cali, Colombia in 1992. He received his B.S degree in Mechanical Engineering in 2018. From 2018 he has been working in the design and development of mechanical systems for industrial applicatins. His research interests include the design, development and characterization of external fixation system for bone transport.

ORCID: https://orcid.org/0000-0001-9974-0591

José Jaime Garcia Alvarez was born in Cali, Colombia in 1954. He received the B.S. in Mechanical Engineering from the Universidad del Valle, Cali, Colombia. Next, he received the M.Sc. and Ph.D. in Mechanics from Michigan State University in 1998. From 1980 to 1998, he was a Lecturer and Assistant Professor at the Universidad del Valle. From 1999 he has been Professor at the Universidad del Valle, Cali, Colombia. He is coauthor of about 50 articles and one invention. His research interests include biomechanics of soft tissues, the development of bone fixation systems, and the mechanical characterization and applications of bamboo.

ORCID: https://orcid.org/0000-0003-2580-805X

Gonzalo Fernando Casanova García was born in Pupiales, Colombia in 1971. He reived the B.S. degree in Mechanical Engineering in 2003 and the M.S degree in Mechanical Engineering in 2006 from Universidad del Valle, Cali, Colombia. Then, in 2013 he received the Ph.D degree in Mechanical Engineering from University of Florida, Gainesville, Florida, USA. From 2007 he has been professor at Universidad del Valle, Cali, Colombia. His research interest include biomechanics of soft tissues, fatigue and failure of mechanical components, composite materials.

ORCID: https://orcid.org/0000-0002-3146-2027 